\title{
EFFECT OF ANTIMONY SUBSTITUTION FOR NIOBIUM ON THE CRYSTAL STRUCTURE, PIEZOELECTRIC AND DIELECTRIC PROPERTIES OF $\left(\mathrm{K}_{0.5} \mathrm{Na}_{0.5}\right) \mathrm{NbO}_{3}$ CERAMICS
}

\author{
H. E. MGBEMERE, G. A. SCHNEIDER \\ Institute of Advanced Ceramics, Hamburg University of Technology \\ Denickestrasse. 15, 21073 Hamburg Germany \\ T. A STEGK \\ Risф National Laboratory, Fuel Cells and Solid State Chemistry Department, \\ DK-4000 Roskilde, Denmark
}

\begin{abstract}
The effect of antimony substitution for niobium on potassium sodium niobate (KNN) ceramic was investigated with respect to the densification behaviour at different sintering temperatures, microstructure and electrical properties. Sb ${ }^{5+}$ was slightly added while simultaneously lowering the amount of $\mathrm{Nb}^{5+}$ and in this study of the $\left(\mathrm{K}_{0.5} \mathrm{Na}_{0.5}\right)\left(\mathrm{Nb}_{1-\mathrm{x}} \mathrm{Sb}_{\mathrm{x}}\right) \mathrm{O}_{3}$ system, $\mathrm{x}$ content was varied from 0 to 14 mol.\% Our results show that $\mathrm{Sb}^{5+}$ slightly increased the optimum sintering temperature for KNN but above 8 mol \%, its resistivity and piezoelectric properties decreased. As the amount of $\mathrm{Sb}^{5+}$ substituted is increased, the structure of the ceramic transformed from orthorhombic to pseudocubic which led to slight shrinkage in the unit cell volume. Microstructural examination revealed that above 10 mol $\%$, a second phase $\left(\mathrm{K}_{2} \mathrm{NaSb}_{3} \mathrm{O}_{9}\right)$ was formed which segregated mainly to the grain boundary while the quantitative EDX analysis showed that there was A-site vacancy due to loss of the alkali elements. The two phase transitions points, Curie temperature $\left(T_{C}\right)$ and the tetragonal to orthorhombic $\left(T_{T-O}\right)$ shifted to lower temperature with increasing $\mathrm{Sb}^{5+}$ content and above $10 \mathrm{~mol} \%$, the $T_{T-O}$ shifted to below room temperature. The dielectric loss slightly increases with increasing $\mathrm{Sb}^{5+}$ content up to $200^{\circ} \mathrm{C}$. There was an improvement in the piezoelectric properties with $\leq 6 \mathrm{~mol} \% \mathrm{Sb}$ content while optimum properties were obtained with $4 \mathrm{~mol} \%\left(K_{P}=0.46, Q_{m}=6.2, N_{P}=2296\right)$.
\end{abstract}

\section{Introduction}

Research into lead free single and polycrystalline potassium sodium niobate (KNN) piezoelectric ceramics started in the 1950'S. Eric Cross investigated the electric double hysteresis in KNN single crystals from which a part of the present phase diagram was obtained ${ }^{1}$. Jaeger et al showed that with hot pressing, the relative density, piezoelectric and electromechanical properties of KNN can be greatly improved ${ }^{2}$. Egerton et al compared the dielectric, piezoelectric and electromechanical properties of $\mathrm{KNN}, \mathrm{KNbO}_{3}$ and $\mathrm{NaNbO}_{3}$ respectively and made the first sketch of the whole phase diagram for $\mathrm{KNN}^{3}$.

With the discovery of ferroelectric properties in lead zirconate titanate (PZT) ceramics, research interest in KNN slowed down due to the fact that the piezoelectric properties obtained in the former far exceeded that from the latter and also due to its complicated processing steps. Environmental concerns and government legislation in recent years have made it possible for research activity into lead free piezoelectric ceramics to increase once again ${ }^{4}$. Efforts are being made in recent times to improve the properties and sinterability of KNN through different synthesis routes while avoiding pressure assisted methods because they are very expensive. Kosec et al ${ }^{5}$ used activated sintering to improve the properties of $\mathrm{KNN}$ by using excess $\mathrm{Nb}^{5+}$, alkali oxides amount and $\mathrm{Mg}$ as additive. Spark plasma sintering has also been used to obtain densities above $99 \%$ of the theoretical density and good piezoelectric properties ${ }^{6}$. Recently, a modified chemical approach with urea to reduce the temperature $\left(550^{\circ} \mathrm{C}\right)$ required for calcination has been reported but the properties were not measured to confirm that good 
piezoelectric properties can be obtained ${ }^{7}$. Saito et al ${ }^{8,9}$ showed that by using texture and isovalent substitution of both the A and B-site elements, the piezoelectric properties in the KNN system can be greatly improved. Combined $\mathrm{Li}^{+}, \mathrm{Ta}^{5+}$ and $\mathrm{Sb}^{5+}$ substitutions have been known to give the highest piezoelectric properties in the $\mathrm{KNN}$ system ${ }^{10,11}$. The effect of $\mathrm{Li}^{+}$on the properties of KNN have also been widely reported in the literature ${ }^{12,13}$ The effect of $\mathrm{Ta}^{5+}$ which is expected to enter the B-site of the structure based on valence and ionic radius has also been reported by Matsubara et $\mathrm{al}^{14} \cdot \mathrm{Li}^{+}$and $\mathrm{Ta}^{5+9,15}$ as well as $\mathrm{Li}^{+}$and $\mathrm{Sb}^{5+}$ on the $\mathrm{A}$ and B-sites respectively of KNN have been reported ${ }^{16,17}$. There is however very little report in the literature on the effect of adding only $\mathrm{Sb}^{5+}$ on the structure and properties of $\mathrm{KNN}$. KNN has been doped with $\mathrm{Sb}$ and $\mathrm{MnO}_{2}$ and the authors reported that $\mathrm{MnO}_{2}$ served only as a sintering aid but it is possible that it has other effects on $\mathrm{KNN}^{18,19}$. In this work, we investigated the effect of substituting $\mathrm{Nb}^{5+}$ with $\mathrm{Sb}^{5+}$ on the piezoelectric, dielectric, crystallographic and microstructural properties of $\mathrm{K}_{0.5} \mathrm{Na}_{0.5} \mathrm{NbO}_{3}$. The objective was to understand through experimental studies, what happens when only $\mathrm{Nb}^{5+}$ is substituted with $\mathrm{Sb}^{5+}$ in $\mathrm{KNN}$.

\section{Experimental Procedure}

$\left(\mathbf{K}_{\mathbf{0 . 5}} \mathbf{N a}_{\mathbf{0 . 5}}\right)\left(\mathbf{N b}_{\mathbf{1 - x}} \mathbf{S b}_{\mathbf{x}}\right) \mathbf{O}_{\mathbf{3}}[\mathrm{x}=(0 ; 0.02 ; 0.14)]$ was synthesized through the mixed oxide route from the following powders; $\mathrm{K}_{2} \mathrm{CO}_{3}, \mathrm{Na}_{2} \mathrm{CO}_{3}$, (99\%), $\mathrm{Nb}_{2} \mathrm{O}_{5}$ and $\mathrm{Sb}_{2} \mathrm{O}_{3}$ (99.9\%) (Chempur Feinchemikalien und Forschungs $\mathrm{GmbH}$, Karlsruhe, Germany). The powders were mixed and attrition milled for $2 \mathrm{~h}$ using ethanol as solvent and $3 \mathrm{~mm}$ zirconia balls as the milling media. They were then calcined at $800^{\circ} \mathrm{C}$ for $4 \mathrm{~h}$ in air; the milling step was repeated to homogenize the powder and also to reduce the average particle size.

The powders were put inside a custom made silicone mould and pressed for 2 min at $500 \mathrm{MPa}$ with a cold isostatic press to obtain pellets with approximately $8.0 \mathrm{~mm}$ diameter and $2.7 \mathrm{~mm}$ thickness. Sintering was carried out at $1080^{\circ} \mathrm{C}, 1090^{\circ} \mathrm{C}$ and $1100^{\circ} \mathrm{C}$ respectively for $2 \mathrm{~h}$ in air.

The relative density values of the samples were calculated using the Archimedes method and after that, they were ground and polished and chemically etched for characterization. The crystal structures of the sintered samples were examined using X-ray diffraction (XRD) with $\mathrm{CuK} \alpha$ radiation $(\lambda=1.54178 \AA$ ) (D8 Discover, Bruker AXS, Karlsruhe, Germany) while the whole powder pattern decomposition was done with the Le Bail fitting method in Topas. Some samples $(x=0,0.02,0.06,0.1,0.120 .14)$ sintered at $1080^{\circ} \mathrm{C}$ were thermally etched at a heating/cooling rate of $10^{\circ} \mathrm{C} / \mathrm{min}$ to $925^{\circ} \mathrm{C}$ for $30 \mathrm{~min}$. Microstructural examination and quantitative Energy dispersive spectroscopy (EDX) (Oxford Instruments) element analysis of the samples were done using a scanning electron microscope (LEO 1530 FESEM, Gemini/Zeiss, Oberkochen, Germany) with EDX capabilities. The standards used were the following natural minerals: Quartz (O), Albite (Na), MAD-10 (K), Nb (Nb), Sb $(\mathrm{Sb})$. Grain size measurements were made using the mean intercept length method from at least six different areas of the SEM image. Silver paint acting as electrodes was applied on both surfaces of the samples for both dielectric and piezoelectric property measurements.

The temperature dependence of the dielectric property of the ceramics was measured from $20 \mathrm{~Hz}$ to $1 \mathrm{MHz}$ with an LCR meter (HP 4284A, Agilent Technologies, Inc., Palo Alto, USA) attached to a heating chamber. Room temperature automated resistance measurement was made using a high resistance meter (4339B Agilent Technologies Inc., Palo Alto, USA) connected to a measuring robot. The samples sintered at $1080^{\circ} \mathrm{C}$ were poled 
at room temperature for $10 \mathrm{~min}$ with a $20 \mathrm{kV} / \mathrm{cm}$ electric field. The planar-mode electromechanical coupling factor $\left(k_{p}\right)$, quality mechanical factor $\left(Q_{m}\right)$ and frequency constant $\left(N_{p}\right)$ were measured by the resonanceantiresonance method with an impedance gain phase analyzer (HP 4192A). Polarization hysteresis measurements were carried out using the standard Sawyer-Tower circuit and a complete dipolar hysteresis measurement was performed in $200 \mathrm{sec}$.

\section{Results and Discussion}

The effects of substituting $\mathrm{Nb}^{5+}$ with $\mathrm{Sb}^{5+}$ and sintering at different temperatures on the relative density values of $\mathrm{KNN}$ is shown in Table 1 . For pure $\mathrm{KNN}$, sintering at $1080^{\circ} \mathrm{C}$ gave the highest density value $(\sim 94 \%)$ which decreased as the sintering temperature was increased. Substitution with $\mathrm{Sb}^{5+}$ up to $8 \mathrm{~mol} \%$ did not show any consistent trend in density but between 10 and $14 \mathrm{~mol} \%$, the density value increased as the sintering temperature was increased. This shows that substitution with substantial amount of $\mathrm{Sb}^{5+}$ to $\mathrm{KNN}$ increases the optimum sintering temperature. This observation is similar to what has been reported in the literature although some $\mathrm{MnO}_{2}$ were added ${ }^{19}$. A possible explanation for the high density value with high $\mathrm{Sb}^{5+}$ amount could be due to the formation of secondary phases when more than $10 \mathrm{~mol} \% \mathrm{Sb}$ is added.

Table 1. Density of $\left(\mathrm{K}_{0.5} \mathrm{Na}_{0.5}\right)\left(\mathrm{Nb}_{1-\mathrm{x}} \mathrm{Sb}_{\mathrm{x}}\right) \mathrm{O}_{3}$ sintered at $1080^{\circ} \mathrm{C}, 1090^{\circ} \mathrm{C}$ and $1100^{\circ} \mathrm{C}$ respectively. The Lattice parameters, resistance, $K_{p}, Q_{m}$ and $N_{p}$ values were obtained from samples sintered at $1080^{\circ} \mathrm{C}$.

\begin{tabular}{|c|c|c|c|c|c|c|c|c|c|c|}
\hline \multirow[b]{2}{*}{ mol \% Sb } & \multicolumn{3}{|c|}{ Bulk Density $\left(\mathrm{g} / \mathrm{cm}^{3}\right)$} & \multicolumn{3}{|c|}{ Lattice parameter $(\AA)$} & \multirow{2}{*}{ 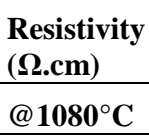 } & \multirow{2}{*}{$\begin{array}{l}K_{p} \\
@ 1080^{\circ} \mathrm{C}\end{array}$} & \multirow{2}{*}{$\begin{array}{l}Q_{m} \\
@ 1080^{\circ} \mathrm{C}\end{array}$} & \multirow{2}{*}{$\begin{array}{l}N_{p} \\
@ 1080^{\circ} \mathrm{C}\end{array}$} \\
\hline & $@ 1080^{\circ} \mathrm{C}$ & $@ 1090^{\circ} \mathrm{C}$ & $@ 1100^{\circ} \mathrm{C}$ & $\mathbf{a}$ & b & c & & & & \\
\hline $\mathbf{0}$ & $4.22 \pm 0.04$ & $4.11 \pm 0.04$ & $3.99 \pm 0.05$ & 3.94744 & 5.64043 & 5.6702 & $\begin{array}{l}1.35 \mathrm{E} 9 \\
\pm 7.93 \mathrm{E} 8\end{array}$ & 0.27 & $1.73 \mathrm{E}+01$ & 3152.7 \\
\hline 2 & $4.18 \pm 0.07$ & $4.25 \pm 0.04$ & $4.23 \pm 0.02$ & 3.94986 & 5.63788 & 5.6643 & $\begin{array}{l}9.13 \mathrm{E} 9 \\
\pm 1.84 \mathrm{E} 9\end{array}$ & 0.38 & $1.24 \mathrm{E}+01$ & 3218.7 \\
\hline 4 & $4.06 \pm 0.03$ & $4.21 \pm 0.02$ & $4.19 \pm 0.01$ & 3.95444 & 5.63569 & 5.6583 & $\begin{array}{l}2.22 \mathrm{E} 11 \\
\pm 1.31 \mathrm{E} 11\end{array}$ & 0.46 & $6.20 \mathrm{E}+00$ & 2253.9 \\
\hline 6 & $4.14 \pm 0.06$ & $4.23 \pm 0.02$ & $4.24 \pm 0.02$ & 3.95432 & 5.63158 & 5.6461 & $\begin{array}{l}1.07 \mathrm{E} 11 \\
\pm 3.52 \mathrm{E} 10\end{array}$ & 0.29 & $1.65 \mathrm{E}+01$ & 2983.6 \\
\hline 8 & $4.3 \pm 0.07$ & $4.18 \pm 0.04$ & $4.19 \pm 0.02$ & 3.95774 & 5.62538 & 5.6381 & $\begin{array}{l}3.66 \mathrm{E} 9 \\
\pm 2.8 \mathrm{E} 9\end{array}$ & 0.33 & 16.4 & 2717.4 \\
\hline 10 & $4.07 \pm 0.05$ & $4.26 \pm 0.02$ & $4.57 \pm 0.03$ & 3.95901 & 5.61942 & 5.6322 & $\begin{array}{l}8.29 \mathrm{E} 8 \\
\pm 1.11 \mathrm{E} 8\end{array}$ & 0.27 & 13.4 & 2634.3 \\
\hline 12 & $4.35 \pm 0.05$ & $4.37 \pm 0.05$ & $4.53 \pm 0.04$ & 3.96627 & 5.61309 & 5.6406 & $\begin{array}{l}3.13 \mathrm{E} 9 \\
\pm 9.2 \mathrm{E} 8\end{array}$ & 0.32 & 10.3 & 3061.7 \\
\hline 14 & $4.29 \pm 0.15$ & $4.33 \pm 0.04$ & $4.56 \pm 0.03$ & 3.96248 & 5.61151 & 5.6343 & $\begin{array}{l}2.12 \mathrm{E} 9 \\
\pm 1.31 \mathrm{E} 9 \\
\end{array}$ & 0.25 & 9.68 & 2275.3 \\
\hline
\end{tabular}

The XRD patterns for $\left(\mathrm{K}_{0.5} \mathrm{Na}_{0.5}\right)\left(\mathrm{Nb}_{1-\mathrm{x}} \mathrm{Sb}_{\mathrm{x}}\right) \mathrm{O}_{3}$ ceramics sintered at $1080^{\circ} \mathrm{C}$ are as shown in Figure 1a. The pattern for the pure KNN showed minute extra peaks which could not be identified from the database while the patterns between 2 and $10 \mathrm{~mol} \% \mathrm{Sb}$ content have a single orthorhombic phase. Above 10 mol \%, extra peaks began to appear and a search and match operation using EVA (commercial software by Bruker) indicated that the extra peaks are related to PDF 01-083-1899 from the International Centre for Diffraction Data (ICDD) database. This phase has a formula $\left(\mathrm{K}_{2} \mathrm{NaSb}_{3} \mathrm{O}_{9}\right)$ with a Laue group (cP64) and crystallizes in a cubic structure. It is an ordering variant of $\mathrm{KSbO}_{3}$ with splitting of one of the cation sites. Lin et al ${ }^{19}$ reported that Sb is believed to diffuse into the KNN lattice and form a solid solution with a single perovskite structure but this occurs when 
its solid solubility limit is not exceeded. It could also be that the addition of $\mathrm{Mn}$ increases the solid solubility limit of $\mathrm{Sb}^{5+}$ in $\mathrm{KNN}$ thereby suppressing the formation of a second phase.
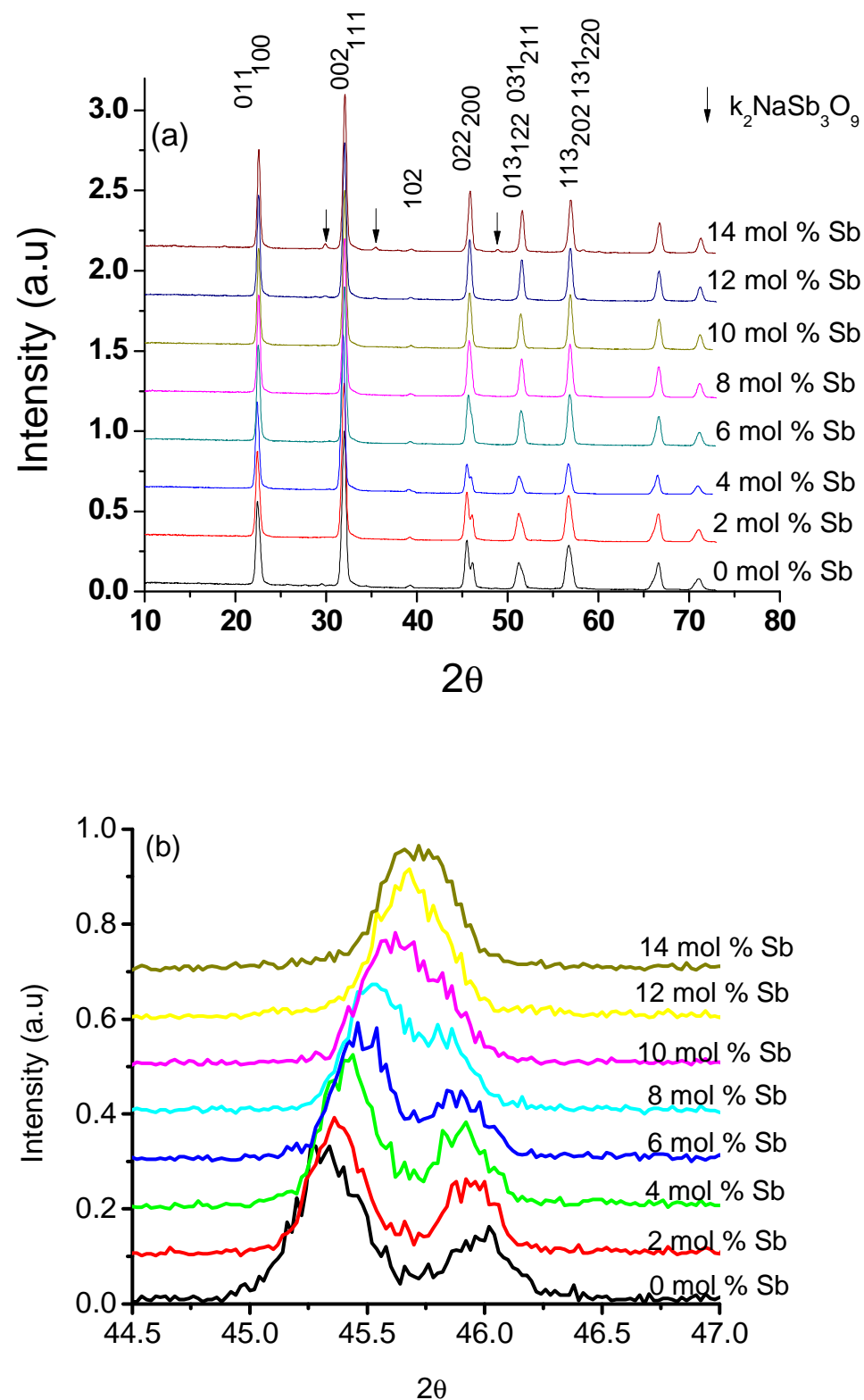

Figure 1. XRD patterns of the polished surfaces of $\left(\mathrm{K}_{0.5} \mathrm{Na}_{0.5}\right)\left(\mathrm{Nb}_{1-\mathrm{x}} \mathrm{Sb}_{\mathrm{x}}\right) \mathrm{O}_{3}$ ceramics sintered at $1080^{\circ} \mathrm{C}$ for $2 \mathrm{~h}$ where $\mathrm{x}$ ranges from 0 to $14 \mathrm{~mol} \% \mathrm{Sb}$ (a) showing $2 \theta$ values from $10^{\circ}$ to $73^{\circ}$ and the extra peaks shown with arrows are related to $\mathrm{K}_{2} \mathrm{NaSb}_{3} \mathrm{O}_{9}$ (b) Enlarged pattern from $44.5^{\circ}$ to $47^{\circ}$ showing the reduction in peak splitting as the amount of antimony substituted is increased.

An enlarged portion of the pattern between $44.5^{\circ}$ and $47^{\circ}$ is shown in Figure $1 \mathrm{~b}$. When the amount of $\mathrm{Sb}^{5+}$ substituted is more than $8 \mathrm{~mol} \%$, the phase transformed from orthorhombic to pseudo-cubic which is similar to related reports in the literature ${ }^{19}$. Based on the difference in ionic radius between $\mathrm{Sb}^{5+}(0.62 \AA)$ and $\mathrm{Nb}^{5+}(0.69$ $\AA$ ), it was expected that there will be an increase in the distortion of the lattice but this did not occur and rather a structure that is pseudo-cubic with increasing $\mathrm{Sb}^{5+}$ content was formed. The excessive lattice vacancies that occur as a result of wide difference in ionic radius lower the solid solution.

$\mathrm{KNbO}_{3}$ with PDF number 01-071-0946 in the ICDD database was used as a reference because it is isostructural with KNN. The whole powder pattern decomposition was carried out using the Le bail method in Topas. With 
increasing amount of $\mathrm{Sb}^{5+}$ in $\mathrm{KNN}$, lattice constant $a$ increases while $b$ and $c$ decreases resulting in a decrease of the volume of the unit cell as shown in Table 1.

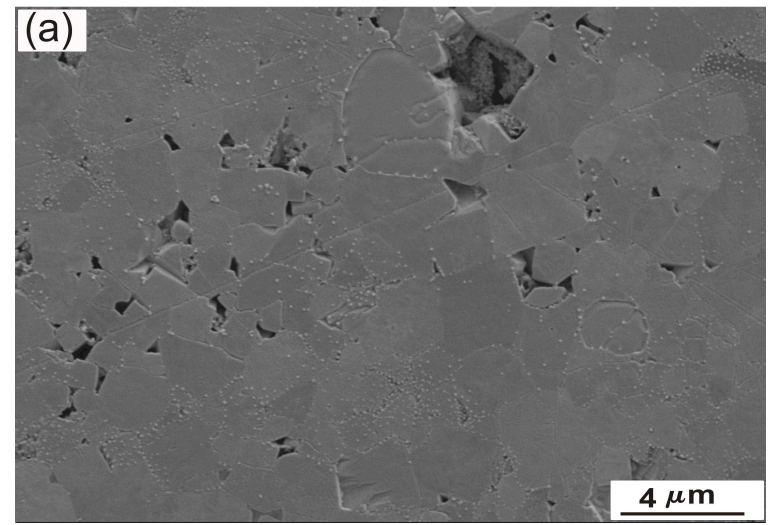

$0 \mathrm{~mol} \% \mathrm{Sb}$

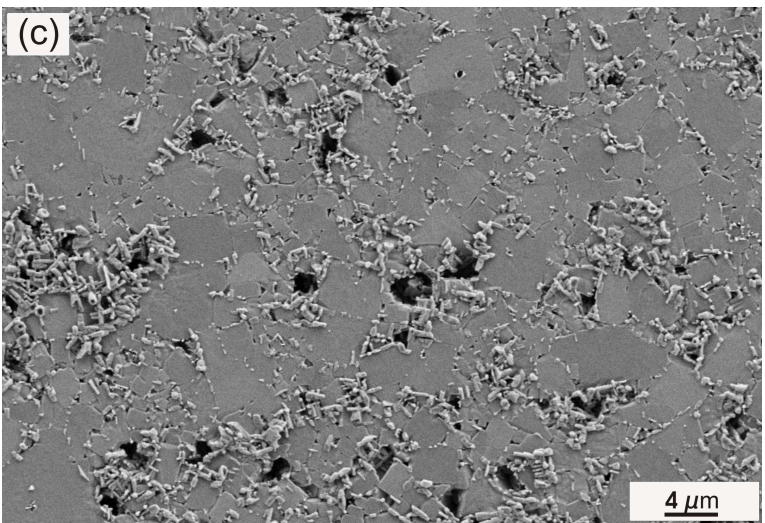

$6 \mathrm{~mol} \% \mathrm{Sb}$

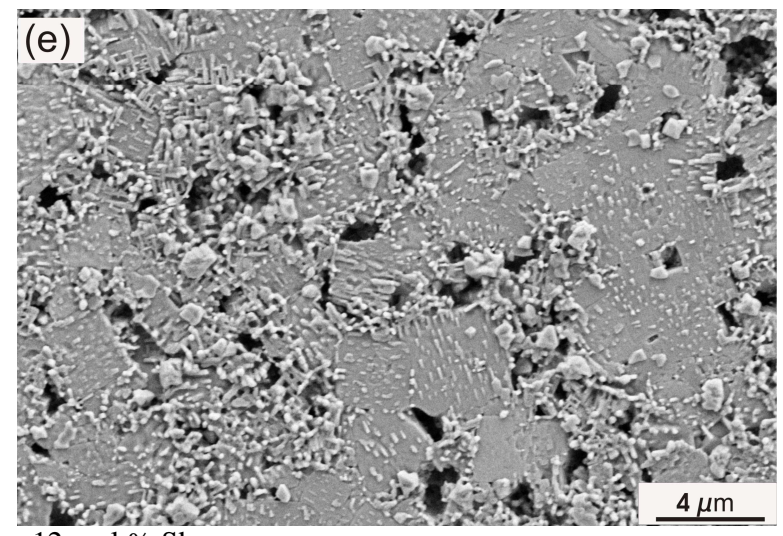

$12 \mathrm{~mol} \% \mathrm{Sb}$

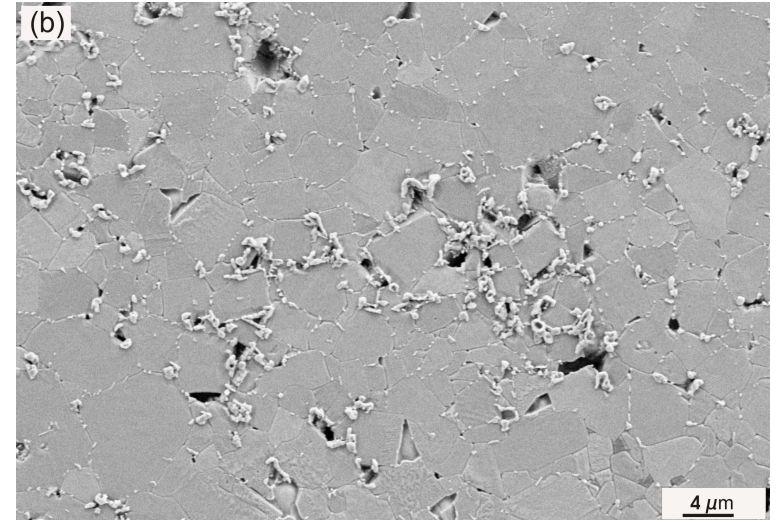

$2 \mathrm{~mol} \% \mathrm{Sb}$

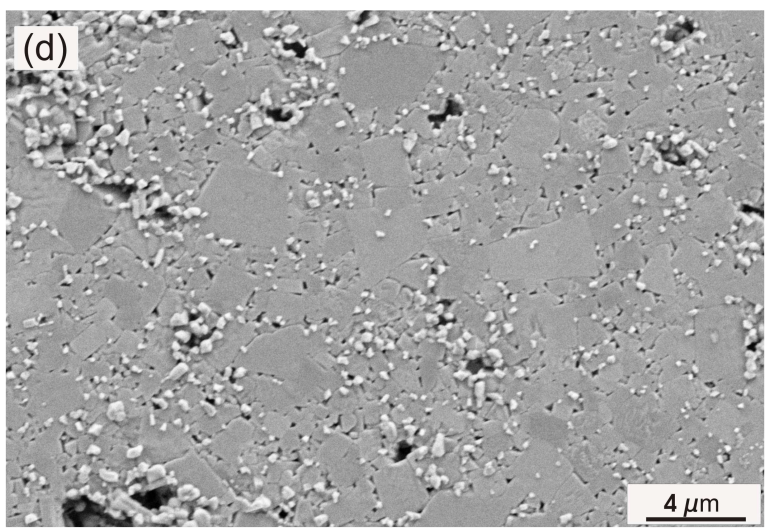

$10 \mathrm{~mol} \mathrm{\%} \mathrm{Sb}$

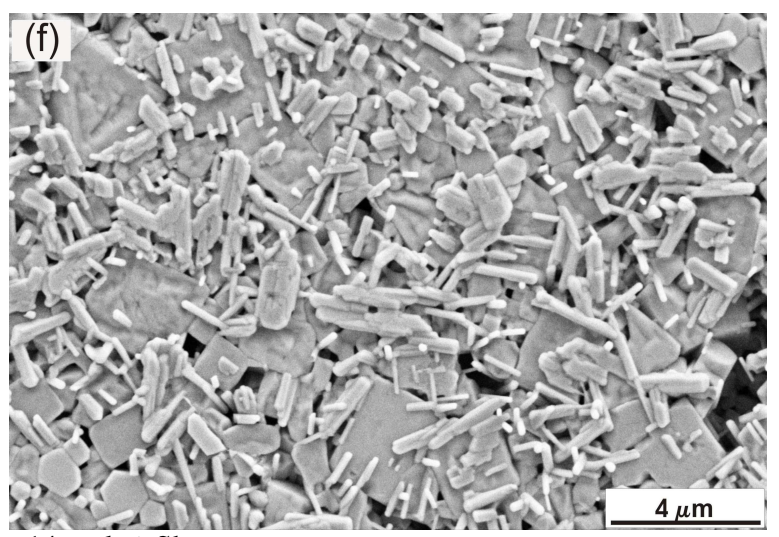

$14 \mathrm{~mol} \% \mathrm{Sb}$

Figure 2. SEM micrographs of KNN ceramics sintered at $1080^{\circ} \mathrm{C}$ and doped with $0,2,6,10,12$ and 14 mol \% Sb (2a, 2b, 2c, $2 \mathrm{~d}, 2 \mathrm{e}$ and $2 \mathrm{f}$ ) respectively. The second phases can be seen clearly on both the grain boundary and inside the grains.

Figure 2a shows the microstructure of a polished and thermally etched pure KNN sample with many small and few big pores located mainly at the triple junction of the grain boundary. The grains have a unimodal size distribution with an average size of $1.51 \pm 0.9 \mu \mathrm{m}$. When $2 \mathrm{~mol} \% \mathrm{of} \mathrm{Sb}^{5+}$ was added (Figure 2b), solute precipitation could be observed mainly at the grain boundaries. Chemical etching in oxide ceramics preferentially dissolve certain grains thereby revealing a significant amount of the grain boundary precipitate ${ }^{20}$. This phenomenon could possibly have occurred for all the samples containing $\mathrm{Sb}^{5+}$ and this boundary segregation occurred mainly due to ionic misfit in the perovskite structure. There was increased grain growth with an average size of $2.64 \pm 1.53 \mu \mathrm{m}$. This size distribution shows that some grains were quite large while 
others were small. As more $\mathrm{Sb}^{5+}$ was substituted for $\mathrm{Nb}^{5+}$, the growth of the new phase also increased forming well ordered clusters which are located mainly at the boundaries (Figure 2c). The size of the grains decreased with increased $\mathrm{Sb}$ content with an average size of $2.47 \pm 1.44 \mu \mathrm{m} .10 \mathrm{~mol} \% \mathrm{Sb}$ content reduced the grain size to $1.24 \pm 0.59 \mu \mathrm{m}$ (Figure 2d). With $12 \mathrm{~mol} \% \mathrm{Sb}^{5+}$ substitution, (Figure 2e), the growth of the new phase became more pronounced forming an interconnected network both inside the grains and at the boundaries. The average grain size increased to $1.5 \pm 0.58 \mu \mathrm{m}$. With $14 \mathrm{~mol} \% \mathrm{Sb}^{5+}$ (Figure 2f), the new phase grew such that they almost completely covered the grains. This observation is similar to the report by Li et al where the $\mathrm{Sb}^{5+}$ rich phase showed plate-like shapes ${ }^{21}$. The grain decreased further with an average size of $1.04 \pm 0.76 \mu \mathrm{m}$.

Quantitative element analysis was also carried out on some of the samples by selecting an area of approximately $1 \mu \mathrm{m}$ by $1 \mu \mathrm{m}$ on the surface of the sample. In addition, scans were carried out on the main and precipitate phase for the sample with $14 \mathrm{~mol} \% \mathrm{Sb}$. The atomic percent of $\mathrm{Na}, \mathrm{K}, \mathrm{Nb}, \mathrm{Sb}$ and $\mathrm{O}$ were normalized assuming $\mathrm{ABO}_{3}$ stoichiometry in all cases and a summary of the quantitative element analysis result for the samples is shown in Table 2. The values were obtained after iterating for 5 times and then normalizing them. In the main grains, while $\mathrm{Nb}^{5+}$ amounts were more or less within the limits, $\mathrm{K}^{+}$and $\mathrm{Na}^{+}$amounts were always deficient for all the samples. In most cases, the measured value for $\mathrm{Na}^{+}$was on average about $30 \%$ less than the expected value while $\mathrm{K}^{+}$was less by about $15 \%$. Sb ${ }^{5+}$ amount was less in most cases by about $20 \%$ while oxygen amount in all cases was higher than the expected value.

The rod-like grains contain the $\mathrm{Sb}^{5+}$ rich phase with close to 3 times more $\mathrm{Sb}^{5+}$ than in the normal grains. This shows that $\mathrm{Sb}^{5+}$ has a tendency to concentrate mainly at the grain boundaries in KNN. There are a lot of combined reasons for this occurrence but one of the dominant driving forces is the difference in electrostatic potential between the main and the new phase. It occurs due to the presence of aliotropic solutes which tend to segregate in the space charge region ${ }^{22}$

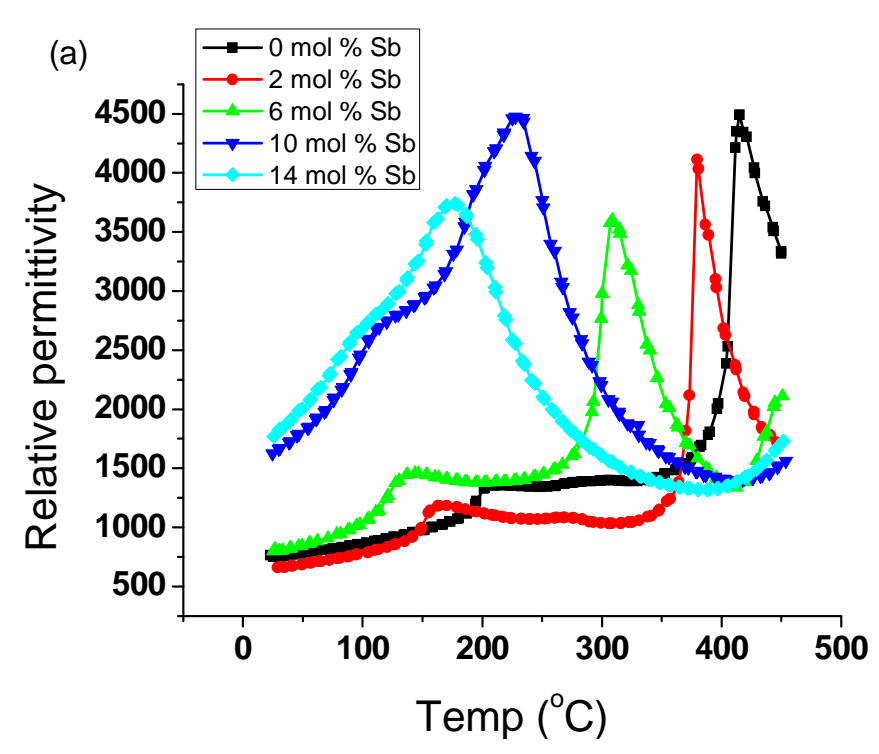

The temperature dependence of the relative permittivity values for the samples measured at $100 \mathrm{kHz}$ is as shown in Figure 3a. A relative permittivity value of about 700 was obtained for pure $\mathrm{KNN}$ at room temperature which is high compared to what has been previously reported in the literature ${ }^{2,3}$. A possible explanation could be the slight change in the stoichiometry of the ceramic due to the presence of A-site vacancies in the perovskite. Substitution with very small amount of $\mathrm{Sb}^{5+}$ initially decreased the dielectric constant values while the reverse was the case when more dopant was added. 


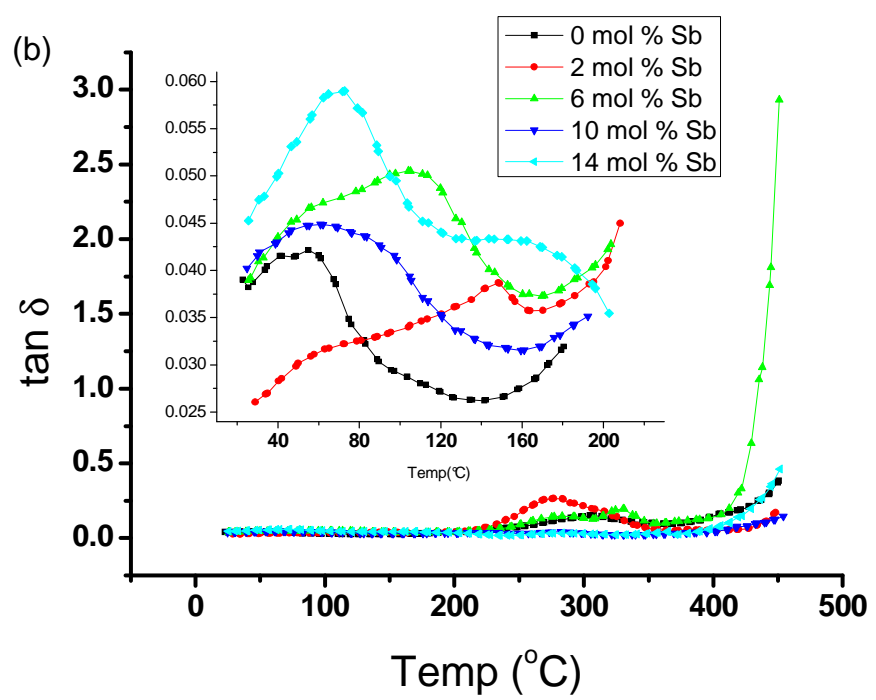

Figure 3 (a) Relative permittivity $\left(\varepsilon_{r}\right)$ values for $\left(\mathrm{K}_{0.5} \mathrm{Na}_{0.5}\right)\left(\mathrm{Nb}_{1-\mathrm{x}} \mathrm{Sb}_{\mathrm{x}}\right) \mathrm{O}_{3}$ ceramics measured at $100 \mathrm{kHz}$ as a function of temperature. (b) Dielectric loss $(\tan \delta$ ) values for the same compositions as a function of temperature measured at $100 \mathrm{kHz}$. The inset shows an enlarged portion of the diagram from $25^{\circ} \mathrm{C}$ to $200^{\circ} \mathrm{C}$.

Both phase transition points $\left(T_{C}\right.$ and $T_{T-O}$ ) shifted to lower temperature with increasing $\mathrm{Sb}^{5+}$ content. The decrease in the lattice constants with increasing $\mathrm{Sb}^{5+}$ substitution accompanies the lowering of the Curie point. The values obtained for both phase transitions for pure $\mathrm{KNN}\left(T_{C}=412^{\circ} \mathrm{C}, T_{T-O}=202^{\circ} \mathrm{C}\right)$ are similar to what has been reported earlier ${ }^{3}$. The $T_{T-O}$ could not be observed for the sample with $14 \mathrm{~mol} \% \mathrm{Sb}$ while the sharpness of the peaks at both $T_{T-O}$ and $T_{C}$ decreased with increasing $\mathrm{Sb}^{5+}$ content indicating decreasing ferroelectricity in the sample.

The temperature dependence of the dielectric loss measured at $100 \mathrm{kHz}$ is shown in Figure 3b. At close to room temperature, $2 \mathrm{~mol} \% \mathrm{Sb}$ gives lower loss values (0.026) compared to pure $\mathrm{KNN}$ but as $\mathrm{Sb}^{5+}$ content is increased, the loss values increases. The inset image inside the figure shows an enlarged region up to $200^{\circ} \mathrm{C}$ indicating differences in loss values with increasing temperature and different amounts of $\mathrm{Sb}^{5+}$. Above $200^{\circ} \mathrm{C}$, the samples with low $\mathrm{Sb}^{5+}$ amount have higher loss values when compared with those with higher $\mathrm{Sb}^{5+}$ content. Generally the loss values of the samples are moderate considering that there are A-site vacancies in the ceramic.

The resistivity values for the samples measured at room temperature are shown in Table 1 . The highest value was obtained for $4 \mathrm{~mol} \%$ while the lowest was for $10 \mathrm{~mol} \%$. Initially Sb substitution increased the resistivity up to $10^{11} \Omega$.cm but it decreased when more than $6 \mathrm{~mol} \%$ was added. This may explain why good polarization could not be obtained for samples with more than $8 \mathrm{~mol} \% \mathrm{Sb}$.

The polarization-electric field behavior of samples with different molar percentages of $\mathrm{Sb}$ is shown in Figure 4. Well saturated hysteresis curves could be obtained for the samples with up to $8 \mathrm{~mol} \% \mathrm{Sb}$ content when a 20 $\mathrm{kV} / \mathrm{cm}$ field but was not successful with more than $8 \mathrm{~mol} \% \mathrm{Sb}$ due to high leakage current. The remnant polarization $\left(P_{r}\right)$ for pure $\mathrm{KNN}$ is $\sim 27 \mu \mathrm{C} / \mathrm{cm}^{2}$ while the coercive field $\left(E_{C}\right)$ is $\sim 8.8 \mathrm{kV} / \mathrm{cm}$ and this high value of $P_{r}$ may probably be due to A-site vacancies in the ceramic. Substitution with $\mathrm{Sb}$ decreases the $P_{r}$ for all the samples but there is no significant change in the $E_{C}(\sim 9 \mathrm{kV} / \mathrm{cm})$. The sample with $4 \mathrm{~mol} \% \mathrm{Sb}$ however has the lowest $P_{r}\left(9.5 \mu \mathrm{C} / \mathrm{cm}^{2}\right)$ and $E_{C}(9.51 \mathrm{kV} / \mathrm{cm})$. 


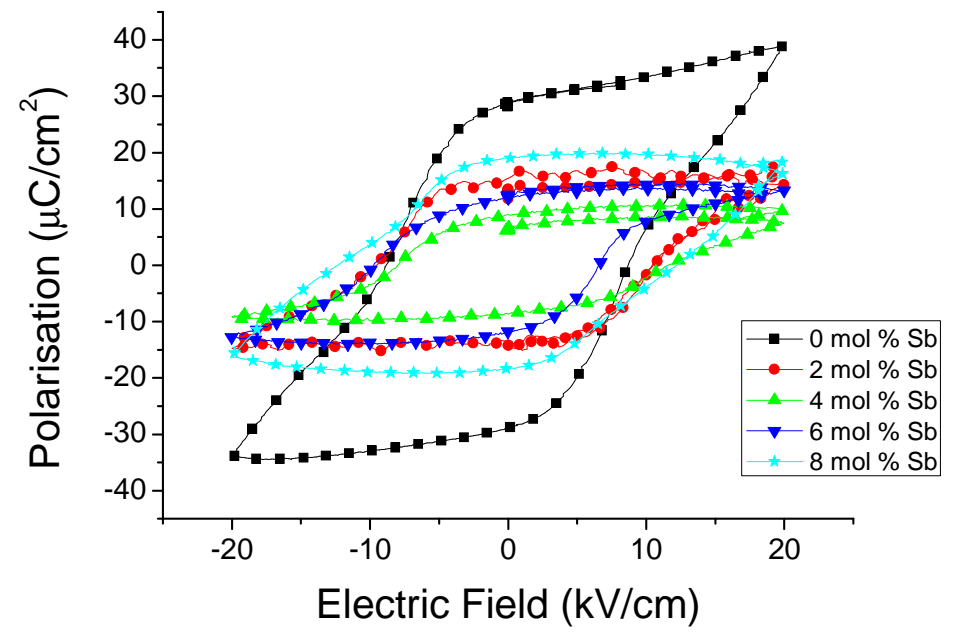

Figure 4. Variation of the polarization field $(P-E)$ hysteresis loops for $\left(\mathrm{K}_{0.5} \mathrm{Na}_{0.5}\right)\left(\mathrm{Nb}_{1-\mathrm{x}} \mathrm{Sb}_{\mathrm{x}}\right) \mathrm{O}_{3}$ ceramics sintered at $1080^{\circ} \mathrm{C}$

The planar-mode electromechanical coupling factor $\left(K_{P}\right)$, quality mechanical factor $\left(Q_{m}\right)$ and frequency constant $\left(N_{P}\right)$ for $\mathrm{Sb}^{5+}$ substituted $\mathrm{KNN}$ measured at room temperature is given in Table 1. Small $\mathrm{Sb}^{5+}$ substitution in KNN increased the $K_{p}$ from 0.277 for pure KNN to 0.46 for 4 mol \% Sb but further substitution decreased the value. The lowest value was obtained for sample the with $14 \mathrm{~mol} \%$. The $Q_{m}$ values for all the samples is low compared to previous reports in the literature ${ }^{19}$. The obtained values ranged from $6.2(4 \mathrm{~mol} \% \mathrm{Sb})$ to 17.3 for pure KNN which indicates that small $\mathrm{Sb}$ substitution initially decreased $Q_{m}$ but it subsequently increased with more $\mathrm{Sb}^{5+}$. Increase in the density of oxygen vacancies enhances $Q_{m}$ by pinning the movement of the domain walls but EDX analysis showed that there was A-site vacancy and this may explain why low $Q_{m}$ values were obtained. The apparent density value of the sample can also affect the obtained $Q_{m}$ with higher values obtained with denser samples. There was no consistent trend in the obtained $N_{P}$ values which range from 2254 (4 mol \% $\mathrm{Sb})$ to $3219\left(2 \mathrm{~mol} \% \mathrm{Sb}\right.$ ). All the samples showed high $N_{p}$ values which indicate high elastic hardness and its suitability for high frequency application.

Table 2. EDX element ratio showing the actual and expected atom $\%$ of the different elements in the $\left(\mathrm{K}_{0.5} \mathrm{Na}_{0.5}\right)\left(\mathrm{Nb}_{1-\mathrm{x}} \mathrm{Sb}_{\mathrm{x}}\right) \mathrm{O}_{3}$ ceramics.

\begin{tabular}{|c|c|c|c|c|c|c|c|}
\hline Element & $\begin{array}{l}\text { Atomic } \\
\%\end{array}$ & $\begin{array}{l}0 \text { mol \% } \\
\text { Sb }\end{array}$ & $\begin{array}{l}2 \mathrm{~mol} \% \\
\mathrm{Sb}\end{array}$ & $\begin{array}{l}6 \mathrm{~mol} \% \\
\mathrm{Sb}\end{array}$ & $\begin{array}{l}10 \mathrm{~mol} \% \\
\mathrm{Sb}\end{array}$ & $\begin{array}{l}14 \text { mol \% } \\
\text { Sb (dark) }\end{array}$ & $\begin{array}{l}14 \text { mol \% } \\
\text { Sb (bright) }\end{array}$ \\
\hline \multirow[t]{2}{*}{ O } & Actual & 65.63 & 67.22 & 65.79 & 65.48 & 68.38 & 70.03 \\
\hline & Expected & 59.99 & 59.98 & 59.99 & 59.99 & 59.99 & 59.99 \\
\hline \multirow[t]{2}{*}{$\mathrm{Na}$} & Actual & 6.53 & 7.19 & 7.21 & 6.91 & 6.58 & 6.31 \\
\hline & Expected & 10.03 & 10.04 & 10.04 & 10.03 & 10.04 & 10.04 \\
\hline \multirow[t]{2}{*}{$\mathbf{K}$} & Actual & 8.33 & 7.94 & 8.36 & 8.79 & 7.92 & 7.86 \\
\hline & Expected & 9.99 & 9.99 & 9.99 & 9.99 & 9.99 & 9.99 \\
\hline \multirow[t]{2}{*}{$\mathbf{N b}$} & Actual & 19.5 & 17.44 & 17.71 & 17.08 & 15.07 & 9.31 \\
\hline & Expected & 19.98 & 19.58 & 18.78 & 17.98 & 17.18 & 17.18 \\
\hline \multirow[t]{2}{*}{ Sb } & Actual & & 0.2 & 0.92 & 1.74 & 2.05 & 6.49 \\
\hline & Expected & & 0.4 & 1.2 & 2 & 2.8 & 2.8 \\
\hline
\end{tabular}




\section{Conclusion}

The effect of substituting niobium with antimony on the crystal structure, piezoelectric and dielectric properties of KNN ceramics produced through the conventional solid state synthesis technique was investigated.

Substituting $\mathrm{Nb}^{5+}$ with $\mathrm{Sb}^{5+}$ in KNN raises its effective sintering temperature and improves densification.

A phase change in the structure of KNN from orthorhombic to pseudo-cubic was observed above $10 \mathrm{~mol} \%$ substitution and the microstructures of the ceramic with different amounts of $\mathrm{Sb}^{5+}$ show rod-like solute segregation mainly at the grain boundary forming and also inside the grains. This second phase $\left(\mathrm{K}_{2} \mathrm{NaSb}_{3} \mathrm{O}_{9}\right)$ was rich in $\mathrm{Sb}^{5+}$ and EDX analysis showed that there were A-site vacancies in the ceramics. The temperatures of both phase transitions were lowered with increasing $\mathrm{Sb}^{5+}$ content such that above 10 mol $\% \mathrm{Sb}$, the $T_{T-O}$ decreased to below room temperature. At temperatures below $100^{\circ} \mathrm{C}$, substituting more $\mathrm{Sb}^{5+}$ led to higher relative permittivity and dielectric values. Saturation polarization was achieved for samples $\leq 8$ mol $\%$ when a $20 \mathrm{kV} / \mathrm{cm}$ field was applied but a good hysteresis loop could not be obtained for those with $>8$ mol \% due to high leakage current. The sample with $4 \mathrm{~mol} \% \mathrm{Sb}$ substitution gave the highest value of $K_{P}$, resistivity and lowest values for $Q_{m}$ and $N_{P}$.

\section{Acknowledgement}

The authors gratefully acknowledge the financial support from DFG under the project: SCHN 372/16-1

\section{Reference}

L. E. Cross, Nature, 178 - 179 (1958).

R. E. Jaeger and L. Egerton, J. Am. Ceram. Soc 45, 209-213 (1962).

L. Egerton and D. M. Dillion, J. Am. Ceram. Soc 42, 438-442 (1959).

E. p. a. t. Council, European Journal 37, 19 (2003).

M. Kosec and D. Kolar, Mat. Res. Bull. 10, 335-340 (1975).

J.-F. Li, K. Wang, B.-P. Zhang, and L.-M. Zhang, J. Am. Ceram. Soc 89, 706-709 (2006).

H. Yang, Y. Lin, J. Zhu, and F. Wang, Powder Technology 196, 233-236 (2009).

Y. Saito, H. Takao, T. Tani, T. Nonoyama, K. Takatori, T. Homma, T. Nagaya, and M. Nakamura, Letters to Nature 432, 84-87 (2004).

Y. Saito and H. Takao, Taylor \& Francis Group 338, 17-32 (2006).

E. K. Akdogan, K. Kerman, M. Abazari, and A. Safari, Appl. Phys. Lett 92, 112908-1-3 (2008).

N. M. Hagh, B. Jadidian, and A. Safari, J. Electroceramics 18, 339-346 (2007).

Y. Guo, K.-i. Kakimoto, and O. Hitoshi, Applied Physics Letters 85, 1-3 (2004).

E. Hollenstein, D. Damjanovic, and N. Setter, Journal of the European Ceramic Society 27, 4093-4097 (2007).

M. Matsubara, K. Kikuta, and H. S., Journal of Applied Physics 97, 1-7 (2005).

E. Hollenstein, M. Davis, D. Damjanovic, and S. Nava, Appl. Phys. Lett 87, 1-3 (2005).

H. E. Mgbemere, R.-P. Herber, and G. A. Schneider, J. Eur. Ceram. Soc. 29, 3237-3278 (2009).

G.-Z. Zang, J.-F. Wang, H.-C. Chen, W.-B. Su, C.-M. Wang, P. Qi, B.-Q. Ming, J. Du, and L.-M. Zheng, Appl. Phys. Lett (2006). Bormanis, and A. Sternberg, Integrated Ferroelectrics 102, 52-61 (2008).

D. Lin, K. W. Kwok, H. Tian, H. Wong, and L.-w. Chan, J. Am. Ceram. Soc. 90, 1458-1462 (2007).

W. D. Kingery, J Am. Ceram. Soc. 57, 74-83 (1974).

H. Li, W. Y. Shih, and W.-H. Shih, J. Am. Ceram. Soc 90, 3070-3072 (2007).

W. D. Kingery, J Am. Ceram. Soc. 57, 1-8 (1974). 